\title{
Motivação no Serviço Público Resulta em Eficiência
}

\author{
Ednayara Souza Alvesı; Géssica de Barros Freire2; Andressa Pacífico Franco Quevedo
}

\begin{abstract}
Resumo: A motivação dos funcionários é imprescindível para o bom desempenho dos profissionais e o alcance dos objetivos organizacionais. Então, busca-se conhecer os fatores determinantes para motivá-los. Para isso, as teorias motivacionais elencam as necessidades dos indivíduos, bem como as suas peculiaridades que direcionam os seus comportamentos. Assim, o objetivo deste estudo é entender os fatores que motivam os servidores e sua relevância para a eficiência da Administração Pública. Este estudo utilizou-se da pesquisa bibliográfica e apresentou, também, como finalidade propiciar a abertura para novas pesquisas sobre fatores motivacionais no serviço público em busca da eficiência, além disso, por meio da aplicação das teorias motivacionais adequadas à realidade organizacional possibilitará uma implementação de melhorias.
\end{abstract}

Palavras-Chave: 1. Administração Pública. 2. Motivação. 3. Eficiência.

\section{Motivation in the Public Service Results in Efficiency}

\begin{abstract}
The motivation of employees is essential to the performance of professionals and the achievement of organizational objectives. So we seek to know the determining factors to motivate them. For this, motivational theories list the needs of individuals and their peculiarities that drive their behavior.The objective of this study is to understand the factors that motivate the servers and their relevance to the efficiency of public administration. This study used the literature and presented also intended to facilitate the opening to new research on motivational factors in public service in pursuit of efficiency also through the application of motivational theories appropriate to the organizational reality will allow an implementation improvements.
\end{abstract}

Keywords: 1. Public Administration. 2. Motivation. 3. Efficiency.

\section{Introdução}

O setor público apresenta um papel determinante e específico devido ao compromisso com o bem-estar coletivo e efetividade dos serviços. Tem-se, portanto, o capital humano como essencial para o desempenho de tais responsabilidades e comprometimento da eficiência com a organização pública (BERGUE, 2012). Pois, as contribuições dos colaboradores possibilitam o alcance dos objetivos estratégicos organizacionais.

\footnotetext{
${ }^{1}$ Graduada em Administração pela Universidade de Pernambuco - UPE. Pós-graduanda em Gestão Pública pela Universidade Federal do Vale do São Francisco - UNIVASF. E-mail: ednayara-souza@hotmail.com

${ }^{2}$ Graduada em Administração pela Universidade Estadual da Paraíba - UEPB. Pós-graduanda em Gestão Pública pela Universidade Federal do Vale do São Francisco - UNIVASF. E-mail: gessicabfreire@ gmail.com

${ }^{3}$ Mestre em Administração pela Universidade Federal de Pernambuco - UFPE. E-mail:andressadm@ gmail.com
} 
Ressalta-se, portanto, que para implementar mudanças nas organizações públicas é indispensável entender sobre a complexidade da cultura organizacional que arraigada à ela estão os traços da cultura brasileira. Também, é primordial a adaptação às mudanças e o atendimento satisfatório à demanda pelos serviços públicos que é influenciado diretamente pelas cobranças coletivas e pressões sociais em prol de melhorias.

Os objetivos do presente trabalho foram: a) Apontar quais expectativas estimulam a motivação do servidor público e como são determinantes para o desempenho profissional, acarretando, portanto, na eficiência dos procedimentos e alcance dos resultados; b) Identificar os fatores motivacionais que interferem no desenvolvimento do serviço público; c) Citar os fatores que contribuem para o alcance de resultados positivos; d) Desenvolver sugestões para pesquisas futuras com propostas de implementação de melhorias, nas quais os servidores sintam-se parte do processo de tal forma que haja um maior comprometimento no desempenho das suas funções.

Trata-se de um trabalho socialmente relevante por ser fundamentado nas teorias motivacionais, pela aplicabilidade do fator comportamental e do princípio da eficiência. Além de conduzir a reflexão a respeito da motivação do servidor perante o serviço público, ainda, tem a finalidade de contribuir para futuras pesquisas que possam implementar melhorias que acarretarão em benefícios, também, à sociedade - clientes do serviço público. Com isso, a partir da prestação do serviço público com eficiência e qualidade, contribuirá, ainda, para a satisfação do interesse e desenvolvimento pessoal e profissional, bem como para o alcance dos objetivos organizacionais de maneira eficiente.

Os próximos tópicos, apresentarão a fundamentação teórica que abordará sobre motivação e as teorias motivacionais; serviço público e eficiência; análise, cultura e comportamento organizacional. Na sequência, os procedimentos metodológicos, as considerações finais e em seguida as referências do presente artigo. Diante disso, a escolha do tema se justifica pela busca do entendimento a respeito da prestação de serviço - em regra - insuficiente ou de má qualidade, bem como sobre a ineficiência da Administração Pública e como a motivação pode reverter essa situação.

\section{Administração Pública e suas Peculiaridades}

Feito um breve estudo no campo do direito público para uma melhor compreensão das peculiaridades da Administração Pública, que tem como objetivo principal desempenhar as atividades administrativas do Estado e realizar políticas que concretizem seus objetivos e atenda aos interesses coletivos, nos termos da lei (HACK, 2010). O desempenho da Administração Pública é decorrente da atividade com pessoas, ou seja, por meio dos servidores públicos. Assim, Matias-Pereira (2010, p. 78) classifica: 
As organizações públicas - responsáveis pela prestação de serviços à sociedade podem ser aceitas como sistemas complexos, interdependentes e dinâmicos. Atuam e interagem no seu ambiente, de forma ininterrupta e de maneira coerente, por meio de pessoas e tecnologias, troca de informações e das estruturas organizacionais.

Em relação ao servidor público, afirma-se que ele passa a integrar o serviço público a partir da aprovação em concurso público, conforme prevê art. 37 da CF/88, sendo investido no cargo com vínculo profissional e efetivo; remuneração paga pelo erário, devido aos serviços prestados ao Estado e à sociedade civil; assim, desempenha as suas funções regidas pela administração pública (BERGUE, 2012).

Dessa maneira, o serviço público compreende a execução de atividades pelo Estado ou a quem ele delegar e tem como finalidade atender aos interesses da coletividade. Considerando o artigo 37 da Constituição Federal Brasileira de 1988, o direcionamento basilar da Administração Pública é fundamentado nos princípios da legalidade, impessoalidade, moralidade, publicidade e eficiência. Eles estabelecem os meios para desempenhar as atividades administrativas e regulam as ações das organizações públicas e dos seus servidores públicos.

Ressalta-se o princípio da eficiência - o mais recente da administração pública - que é de relevância no âmbito do serviço público. Assim, "a eficiência consiste em realizar as atribuições de uma função pública com competência, presteza, perfeição e rendimento funcional, buscando com isso, superar as expectativas do cidadão-cliente" (VIEIRA et al., 2011 p. 5). Este princípio visa aperfeiçoar a prestação do serviço, de modo que seja de qualidade e executado da melhor maneira. Com isso, busca otimizar os resultados pretendidos, como também, regular a atuação dos servidores públicos.

À medida que a organização pública atende com responsabilidade aos interesses da sociedade e cumpre com os princípios da administração pública para o bem comum, há uma complexidade que envolve o âmbito do setor público e variáveis específicas, ligadas à dinâmica comportamental dos servidores públicos. Nessa perspectiva, Bergue (2012, p. 18) reforça que:

A motivação das pessoas no ambiente do serviço público, exemplo de outros fenômenos neste mesmo contexto, tomado em contraste com organismos da esfera privada, é revestida de especial complexidade decorrente de um número substancial de características de natureza cultural, política, econômica e legal que particularizam esse setor.

Nesse contexto, a organização pública depende do recurso humano para a consecução dos seus objetivos, os quais estão sujeitos às atividades para tal fim e paralelamente à consecução dos seus objetivos pessoais. Essa relação existente de trabalho apresenta mudanças nos fenômenos comportamentais do setor público, o que interfere em resultados organizacionais e pessoais, e 
Id on Line Revista Multidisciplinar e de Psicologia

Id on Line Multidisciplinary and Psychology Journal

consequentemente, no desempenho das atividades e da prestação do serviço público que é influenciado diretamente pela motivação do servidor.

É necessário, portanto, compreender a importância do recurso humano no âmbito do serviço público, analisar a relação de trabalho e os níveis de motivação diante das expectativas profissionais e pessoais, para então implantar estratégias que contribuam para o comportamento humano e o desempenho eficiente e satisfatório na prestação do serviço público de qualidade e eficiência.

\section{Relação do Comportamento e da Cultura Organizacional}

A cultura organizacional define os valores da empresa e direciona quais os comportamentos que as pessoas devem adotar, por isso, há uma interrelação importante sobre o comportamento e a cultura organizacional.

De acordo com Knapik (2012, p. 23) "a cultura organizacional é composta por regras formais e informais que direcionam a forma de agir, pensar, perceber e compartilhar das pessoas que fazem parte de uma organização, direcionando os esforços de todos para alcançar os objetivos da empresa". Assim, o colaborador passa a integrar a organização, relacionar-se com os demais e sentir que faz parte da equipe ao adequar-se à cultura, passa a comprometer-se com os processos e objetivos organizacionais, logo, irá contribuir com a produtividade.

Ainda nessa perspectiva e com definições complementares, Maximiano (2004, p. 242) afirma que "a cultura organizacional abrange normas informais de conduta, hábitos, crenças, valores e preconceitos, cerimônias e rituais, símbolos e outros comportamentos". Então, a cultura destaca as características da organização e orienta o comportamento dos seus membros.

Além de diferenciar as empresas por meio das normas, hábitos e valores predominantes, a cultura organizacional proporciona um senso de identidade aos colaboradores e estimula a estabilidade da equipe; tende a facilitar um maior comprometimento com os objetivos organizacionais; também, orienta as atitudes e comportamentos dos funcionários (ROBBINS, 2005).

É importante ressaltar que embora existam organizações com padrões socioeconômicos similares elas apresentam características peculiares, justamente devido à cultura implantada de acordo com as crenças e valores de cada uma, que interferem no modelo de gestão adotado, no comprometimento dos colaboradores e outras variáveis.

Existem culturas mais firmes e sólidas, portanto, é mais difícil a adaptação ou, até mesmo, a implementação de mudanças. Por outro lado, há organizações mais flexíveis que identificam a inovação como vantagem competitiva. Bergue (2010) defende que o setor público brasileiro apresenta traços de paternalismo, como: vantagens e concessões. Ademais, destaca a heterogeneidade 
encontrada na Administração Pública e traços culturais pertinentes a tais organizações, são eles: constância no ritmo e ambiente de trabalho, além da estabilidade - que será discutida adiante.

Com isso, as organizações são influenciadas diretamente pela cultura do ambiente em que estão inseridas o que acaba afetando, também, a atuação dos servidores. Conforme explana MatiasPereira (2010, p. 79) “as características existentes na cultura de organizações públicas - que em geral possuem burocracias centralizadoras e estruturas rígidas - tendem a se refletir na forma de atuar e de comportar dos seus servidores".

Já o comportamento organizacional estuda os grupos e indivíduos e seus comportamentos. Dessa maneira, Chiavenato (2012, p. 225) afirma que: "por ser um sistema cooperativo racional, a organização somente pode alcançar seus objetivos se as pessoas que a compõe coordenarem seus esforços a fim de alcançar algo que individualmente jamais conseguiriam." Assim, por meio dele é possível entender como as organizações funcionam, apresentam equipes integradas, são produtivas e alcançam os melhores resultados.

Para Robbins (2005, p. 6) "o comportamento organizacional é um campo de estudos que investiga o impacto que indivíduos, grupos e a estrutura têm sobre o comportamento dentro das organizações com o propósito de utilizar este conhecimento para melhorar a eficácia organizacional". Portanto, é imprescindível o conhecimento - por parte dos administradores - do comportamento organizacional e das características pessoais dos indivíduos para que atuem no direcionamento dos funcionários de maneira eficiente. Porque, ele abrange aspectos comportamentais dos indivíduos e também dos grupos formados dentro das organizações.

Diante disso, a maneira com a qual o gestor lida com os funcionários e os direciona afeta diretamente o comportamento das pessoas, a exemplo disso, se existir a falta de autonomia impossibilitará a utilização de competências adquiridas, a inovação nos procedimentos e na organização como um todo, entre outros aspectos (BERGUE, 2012).

Fazendo uma correlação entre os valores compartilhados pela empresa e a busca pelos objetivos organizacionais, percebe-se que se o gestor souber coordenar sua equipe e fortalecer a cultura de tal forma que os colaboradores acatem e trabalhem para alcançar objetivos comuns, consequentemente, os resultados serão atingidos de maneira satisfatória.

Pois, um clima organizacional favorável é decorrente, também, dessa integração de gestão eficaz com colaboradores motivados e que compartilham dos mesmos valores e objetivos organizacionais. De acordo com Knapik (2012, p. 21): “o clima organizacional é o ambiente psicológico que existe em um departamento ou empresa, é aquela condição interna percebida pelas pessoas e que influencia os comportamentos delas". Entende-se, portanto, que o clima organizacional envolve a subjetividade, logo, é definido pelas percepções e sentimentos das pessoas em relação ao ambiente de trabalho, que pode gerar satisfação ou insatisfação dos colaboradores. 
Dessa forma os gestores necessitam de tais conhecimentos para o alcance dos objetivos organizacionais, ainda, é fundamental possuir habilidades interpessoais para uma gestão eficiente, aliando o desenvolvimento organizacional à satisfação e realização pessoal, uma vez que os resultados são obtidos através desse comportamento humano e por meio da motivação dos colaboradores. Posto isso, torna-se necessário aprofundar o estudo da motivação e os fatores determinantes para o bom desempenho profissional.

\section{Conceitos Básicos de Motivação}

O tema motivação vem sendo amplamente pesquisado por vários autores, os quais têm contribuído com novos conceitos e formulado as teorias para um melhor entendimento dos fatores motivacionais e sua aplicabilidade ao comportamento humano.

Para melhor compreensão, a origem etimológica da palavra motivação deriva do latim motivos, movere, que significa mover. Na sua originalidade, a palavra indica "o processo pelo qual o comportamento humano é incentivado, estimulado ou energizado, por algum tipo de motivo ou razão" (MAXIMIANO, 2009, p. 180). Então, a motivação é decorrente dos estímulos internos ou externos que direcionam para a ação, esforço e comprometimento.

Questiona-se a respeito da possibilidade e dificuldades de conseguir motivar alguém, uma vez que a motivação é inerente a cada indivíduo conforme as suas necessidades. No entanto, "é possível manter pessoas motivadas quando se conhece suas necessidades e se lhes oferece fatores de satisfação para tais necessidades" (BRUNELLI 2008, p. 28 apud BERGAMINI 1997b).

De acordo com o que Maximiano (2009) destaca, o esforço ou a ação que estimula uma pessoa para o desempenho no trabalho é resultante da interação de motivos complexos, internos e externos:

- Motivos internos: relacionados à própria pessoa (habilidades, experiências de vida, crenças e valores), e ao potencial do indivíduo ao valorizar certos comportamentos e ser capaz de realizar determinadas tarefas. São, essencialmente, impulsos interiores de natureza fisiológica e psicológica que são afetados por fatores sociológicos (grupos, comunidade).

- Motivos externos: ligados aos estímulos e/ou incentivos vindos do ambiente ou dos objetivos pretendidos. Eles satisfazem as necessidades ou despertam um sentimento positivo ou recompensa desejada pelas pessoas. Os motivos externos são a atividade desempenhada, o ambiente no qual a atividade é feita, as recompensas, os valores sociais, e os padrões estabelecidos.

Nesse sentido, a motivação é vista como motivo/força que estimula o indivíduo para ação, ou seja, a desempenhar com disposição e esforço, além disso, a realizar com qualidade e eficiência as atividades da organização para o alcance dos seus anseios individuais.

Conforme a definição de Vieira et al. (2011, p. 5) "a motivação é o desejo de exercer altos níveis de esforço em direção a determinados objetivos organizacionais, condicionados pela capacidade 
de satisfazer algumas necessidade individuais." O autor afirma, ainda, que ela está relacionada com os seguintes aspectos: objetivo, esforço e necessidade.

Na mesma linha, Robbins (2005) define que a motivação envolve o direcionamento e os esforços despendidos para o alcance dos objetivos, além disso, enfatiza que a persistência torna-se fundamental no processo em busca dos resultados; uma vez que o indivíduo motivado permanecerá se empenhando até alcançar a meta determinada.

Portanto, motivado e focado nos objetivos organizacionais, o indivíduo passa a direcionar os esforços para o benefício da organização, intensificando-os para a realização das atividades e alcance dos resultados desejados.

Dessa maneira, a motivação é vista como principal componente para o enfoque comportamental e busca entender quais fatores internos e externos diante dos aspectos e características do ambiente organizacional influenciam o comportamento humano. Com isso, para um melhor aprofundamento do assunto sobre motivação serão apresentadas a seguir as principais teorias motivacionais.

\section{Teorias Motivacionais}

As principais teorias motivacionais serão apresentadas e são categorizadas em Teorias Clássicas e Teorias Contemporâneas; também, são classificadas em Teorias de Conteúdo que analisam o comportamento humano e quais as necessidades que motivam o indivíduo a tomar determinados comportamentos, elas definem taxativamente os fatores de motivação. Enquanto que as Teorias de Processo abordam sobre o funcionamento do processo de motivação e são baseadas nas crenças e valores do indivíduo, desse modo, há uma combinação de fatores intrínsecos e extrínsecos.

\section{Teorias Clássicas}

\section{Teoria da Hierarquia das Necessidades}

As necessidades individuais existem e precisam ser atendidas, com isso, esta teoria defende que os cinco tipos de necessidades são enumeradas em uma ordem hierárquica - desde as necessidades básicas, de segurança, sociais, de estima, até as de autorrealização. E, isso gera disposição e interesse de realizar atividades para alcançar os objetivos.

Defendida por Abraham Maslow, a Teoria da Hierarquia das necessidades é, provavelmente, a mais conhecida dentre as teorias de motivação de conteúdo. Ela foi formulada na hipótese de que 
Id on Line Revista Multidisciplinar e de Psicologia

Id on Line Multidisciplinary and Psychology Journal

dentro de cada indivíduo há uma hierarquia de necessidades e as pessoas são motivadas a atendê-las, as quais são manifestadas em graus de importância (ROBBINS, 2005).

Maslow defende que à medida que uma necessidade é satisfeita, a próxima torna-se dominante no comportamento do indivíduo. Ele organizou as necessidades humanas em cinco níveis hierárquicos, apresentadas em formato de uma pirâmide, assim estruturada:

- Necessidades fisiológicas: são indispensáveis para a sobrevivência do indivíduo;

- Necessidades de segurança: vinculadas à proteção contra ameaças externas;

- Necessidades sociais: aceitação do indivíduo no grupo ou sociedade;

- Necessidades de estima: busca de status e valorização social;

- Necessidades de autorrealização: alcance do crescimento profissional desejado e da busca contínua pelo autoaperfeiçoamento.

Portanto, os tipos de necessidades elencadas seguem um nível de prioridade que abrangem desde o fisiológico até a autorrealização. Assim, uma vez atendida determinada necessidade a próxima hierarquicamente superior passa a ser objeto de desejo, de tal forma que motiva o indivíduo a buscar meios para satisfazê-la.

\section{Teoria dos Dois Fatores - Frederick Herzberg}

Herzberg analisou o comportamento e a motivação das pessoas dentro das organizações, ele considerou que tanto o ambiente externo como o trabalho em si são fatores determinantes na análise da motivação.

Assim, a teoria é dividida em fatores motivacionais (relacionados à autorrealização) que defende que o principal motivador para o sucesso ou fracasso é o próprio indivíduo, pois, estes fatores estão intrinsecamente ligados a ele, e os fatores higiênicos que têm relação com o ambiente de trabalho.

Nesse sentido, Chiavenato (2012) apresenta os dois fatores que orientam o comportamento das pessoas no ambiente de trabalho, são eles:

- Fatores higiênicos - estão fora do controle das pessoas, ou seja, são extrínsecos e, com isso, determinados pelo contexto em que é realizado o trabalho. Afirma-se, ainda, que quando atingidos da melhor maneira conseguem evitar a insatisfação, mas não provocam a satisfação dos colaboradores. A exemplo: o salário e vantagens recebidas, o clima organizacional, condições de trabalho e políticas da organização.

- Fatores motivacionais - por estarem relacionados ao cargo e execução das tarefas, são fatores intrínsecos e envolvem os sentimentos das pessoas. Assim, estão relacionados com o desenvolvimento pessoal e profissional que se não for positivo, provocará o desinteresse e a apatia dos 
trabalhadores - um crescimento da desmotivação. Então, quando adequados aumentam a satisfação das pessoas no trabalho; caso contrário, evitam a satisfação dos trabalhadores. A exemplo: o desempenho do trabalho, a realização pessoal, o reconhecimento, o progresso profissional e a responsabilidade.

Para corroborar, Maximiano (2015) explica que a satisfação é decorrente somente dos fatores intrínsecos, ou seja, a autorrealização e situações relacionadas ao trabalho como as oportunidades de aprendizagem e crescimento profissional; e que os fatores extrínsecos são insuficientes para gerar a motivação para o trabalho já que ela é consequência do entusiasmo com o trabalho que ocorre por meio do desenvolvimento de aptidões e habilidades.

Então, os fatores higiênicos influenciam a satisfação em relação ao local onde o trabalho é realizado, e são suficientes apenas para evitar que as pessoas fiquem desmotivadas. Já a motivação para o trabalho decorre da possibilidade de crescimento pessoal e enquadra-se nos fatores motivacionais que são relacionados às tarefas desempenhadas. Logo, o ambiente não provoca a motivação já que ela, de acordo com esta teoria, é obtida por meio do próprio trabalho.

\section{Teorias Contemporâneas}

\section{Teoria da Equidade}

A Teoria da Equidade foi desenvolvida a partir de estudos fundamentados no fato de que os indivíduos avaliam as recompensas recebidas no trabalho e acreditam que o tratamento deve ser justo quando comparado com a execução das atividades dos outros trabalhadores, existindo assim a equidade. De acordo com (Vieira et al. 2011, p.15) "essa teoria, desenvolvida por J. Stacy Adams, propõe que as pessoas sejam motivadas a procurar uma equidade social nas recompensas que esperam pelo seu desempenho."

A complementar, um dos elementos centrais para o entendimento da teoria da equidade, é reconhecer que o indivíduo está mais atento às situações no ambiente de trabalho quando faz constantes comparações de sua relação entre os esforços desempenhados e remunerações percebidas com as alcançadas pelos colegas, essas comparações são capazes de afetar o comportamento desse indivíduo (BERGUE, 2012).

Defende-se, portanto, o equilíbrio, ou seja, a justiça de tratamento que é dada aos colaboradores. Para Maximinao (2004, p. 283) a base desta teoria "é a crença de que as recompensas devem ser proporcionais ao esforço e iguais para todos". Assim, quando as comparações forem feitas o esperado é que haja a equidade, logo, o senso de justiça é forte influenciador nas motivações. 
Para que haja o equilíbrio é necessário que a recompensa seja igual para os trabalhadores que realizaram o mesmo esforço (proporções iguais). Se isso ocorrer, pode-se afirmar que existiu a equidade, ou seja, a situação foi justa. No entanto, se as proporções forem desiguais a percepção que prevalecerá será a de injustiça, o que poderá influenciar no grau de esforço que os trabalhadores dedicam às suas tarefas. Para um melhor direcionamento, Robbins (2005, p. 147) relata que:

\begin{abstract}
Os executivos deviam pensar em compartilhar abertamente as informações sobre como as decisões de recompensas são tomadas, buscar procedimentos coerentes e sem vieses e se engajar nessas práticas para aumentar a percepção da justiça de processo. Tendo aumentada a percepção de justiça de processo, os funcionários passam a ver seus chefes e a organização de maneira positiva, mesmo que estejam insatisfeitos com sua remuneração, oportunidades de promoção e outras conquistas pessoais.
\end{abstract}

Diante disso, pode-se afirmar que a transparência do processo é uma das atitudes que irá amenizar as consequências das percepções negativas dos trabalhadores e suas respectivas ações em decorrência disso. Maximiano (2004, p. 284) assegura que se for perceptível a falta de equidade acarretará nos seguintes comportamentos: alteração no esforço exercido; alteração nos resultados produzidos; distorção da auto-percepção, distorção da percepção dos outros; escolha de outra referência e abandono da situação.

Assim, a avaliação decorre do esforço aplicado na atividade e o resultado obtido com isso; a partir daí surgirá a comparação - por parte do trabalhador - da proporção entre execução e desempenho com a proporção de outros funcionários, e se injustiças forem percebidas os trabalhadores atuarão para corrigir tal situação. O resultado poderá gerar maior ou menor produtividade, melhoria ou redução da qualidade da produção, aumento do absenteísmo ou demissão voluntária.

A referida teoria leva em consideração que a recompensa deve ser proporcional ao esforço realizado e igualitária para todos, assim, a motivação aplica-se ao tratamento justo.

\title{
Modelo Contingencial de Vroom
}

Esta teoria defende que o trabalhador sente-se motivado quando acredita na recompensa decorrente do seu esforço. Logo, a motivação será o resultado da integração entre expectativas e recompensas, que tende a acarretar em maior produtividade. De acordo com a Teoria de Vroom, os principais componentes capazes de provocar no indivíduo a motivação para produzir são: as expectativas, as recompensas e a relações entre expectativas e recompensas.

A teoria da expectativa, atualmente, é uma das explicações que mais se adéquam à realidade e, por isso, torna-se a mais aceita. Para Robbins (2005) ela aponta os motivos pelos quais os trabalhadores não desempenham da melhor maneira as suas atividades e o porquê da falta de 
motivação para o trabalho. Ainda, Maximiano (2015) afirma que ela é a principal explicação a respeito da interação entre os motivos internos e estímulos do ambiente.

A teoria da expectativa de Victor Vroom defende que a motivação do indivíduo irá variar de acordo com as expectativas empregadas nas recompensas devido ao trabalho realizado. Nesse sentido, Robbins (2005) aponta que nesta teoria o indivíduo sente-se motivado quando acredita que seu esforço irá resultar em boa avaliação de desempenho, e essa avaliação irá resultar em recompensas organizacionais que irão satisfazer suas metas pessoais. A definição desses fatores determinantes é dada por Chiavenato (2012) da seguinte maneira:

- Expectativas - são geradas pela crença de que o esforço levará ao alcance dos objetivos individuais desejados;

- Recompensas - abrange a percepção de que os objetivos individuais serão alcançados de acordo com produtividade;

- Relações entre Expectativas e Recompensas - quando o nível de produtividade do colaborador é influenciado por ele mesmo com o intuito de atingir suas expectativas, decorrentes da recompensa.

Desse modo, o autor supracitado assegura que a produtividades dos funcionários dependerão da relação desses fatores determinantes. Nessa perspectiva, "a essência da teoria da expectativa é a compreensão dos objetivos de cada indivíduo e as ligações entre esforço e desempenho, desempenho e recompensa e, finalmente, entre recompensa e alcance das metas pessoais" (ROBBINS, 2005, p. 149). Portanto, ele defende que a teoria enfoca três relações, a saber: relação esforço-desempenho; relação desempenho-recompensa; relação recompensa- metas pessoais.

É possível afirmar que quando o indivíduo não se sentir motivado, após a análise dessas três relações da teoria, depreende-se que a sua percepção foi que houve muito esforço de sua parte e a obtenção de pouco ou nenhum reconhecimento diante do seu desempenho, e que as recompensas não foram atrativas e/ou adequadas às suas metas pessoais.

Diante disso, para que as vantagens salariais ou os incentivos pelo desempenho cumpram a função de motivar o funcionário é necessário que estejam adequados aos objetivos pessoais. Assim, haverá a motivação de acordo com a expectativa do colaborador, que se empenhará para alcançar os objetivos organizacionais à medida que irá buscar atingir suas metas pessoais.

Se o empregado percebe que o alto nível de desempenho poderá levá-lo a alcançar suas metas pessoais, decidirá esforçar-se para assim atingir graus de atuação cada vez mais elevados. Em caso contrário, se a sua percepção é a de que a probabilidade de alcançar as metas desejadas não é condizente com o esforço a ser dispendido, seu desempenho tenderá a decair (RAMOS, 1990, p. 132).

Então, de acordo com essa teoria o processo de motivação depende das escolhas e expectativas para alcançar objetivos. Maximiano (2015) sintetiza a teoria da expectativa da seguinte maneira: o 
cumprimento da obrigação de maneira eficiente é decorrente do esforço e dedicação por parte do funcionário, que somente ocorrerá se o profissional reconhecer a importância do resultado do desempenho e objetivar a recompensa, com isso, surge a motivação que acarretará em esforço intenso para atingir os resultados.

Esta teoria analisa os fatores que interferem na produtividade e enfatiza a importância das diferenças individuais, entre elas as necessidades, ao evidenciar o comportamento das pessoas diante das situações. Para Vroom, os colaboradores analisam se a sua alta produtividade contribuirá para o alcance dos seus objetivos pessoais, se isso for positivo resultará em um aumento do seu desempenho.

É importante ressaltar que as recompensas apresentam valores diferentes para cada indivíduo, além disso, que as percepções individuais influenciam os comportamentos para o alcance dos resultados. Assim, a produtividade tende a aumentar quando o colaborador acredita que o seu desempenho está relacionado com as recompensas desejadas.

Em síntese, Robbins (2005) afirma a respeito da teoria que os fatores a seguir resultam na redução da motivação, são eles: se o trabalhador acreditar que independente do seu esforço não haverá melhoria na avaliação de desempenho; embora seja obtida uma boa avaliação de desempenho, não acarretará em recompensa organizacional; por mais que exista recompensa ela não é atraente para o funcionário. Outro fator importante citado é a respeito da individualização das recompensas e que os efeitos motivacionais devem se adequar às necessidades de cada indivíduo.

O conhecimento das teorias é imprescindível pelo fato de que é possível analisar e identificar a melhor maneira de motivar as pessoas, já que os indivíduos despertam interesses e necessidades diferentes. Portanto, sugere-se que as políticas organizacionais estejam em consonância com as expectativas dos empregados, caso isso não ocorra acarretará em grande índice de desmotivação que tende a aumentar a rotatividade de pessoal, a queda da produtividade, entre outros fatores.

A finalidade do estudo dessas teorias é entender o impacto da motivação sobre o desempenho das pessoas no ambiente de trabalho, bem como adaptá-las à realidade das organizações e utilizá-las, nos casos práticos, para implementar ações benéficas. Para uma melhor análise, a seguir serão apresentadas as dificuldades de trabalhar a motivação no setor público, decorrentes - principalmente da estabilidade.

\section{Estabilidade: Fator Motivacional que Interfere no Desempenho do Serviço Público}

Quando o indivíduo direciona suas necessidades na busca pela segurança e proteção financeira e foca seus objetivos pessoais para aprovação em concurso público, inicialmente, a estabilidade garantida no setor público é vista como benefício e fator motivacional. Uma vez que o indivíduo tende a ficar mais tranquilo pela segurança de estar empregado, com baixa possibilidade de demissão, 
quando comparado ao setor privado, podendo-lhe assegurar maior satisfação no desempenho de suas atividades e a eficiência na prestação do serviço público. Conforme Torres (2011, p. 4):

A garantia da estabilidade do servidor público deve ser analisada como um benefício do servidor e fonte motivacional da excelência na prestação de serviços à sociedade, e não entendido como um privilégio que confere a vitaliciedade do cargo ou função pública ao servidor. Embora, a Constituição Federal (art.41/88) assegure ao Estado a faculdade da demissão, é garantido ao servidor o amplo direito de defesa, dificultando as ações demissionais na administração pública.

Para garantir essa efetiva permanência no funcionalismo público, conforme prevê artigo 41 da Constituição Federal, é necessário passar por um período de três anos de avaliação no estágio probatório e após a sua aprovação, que assegura plenas condições de desempenhar o cargo público, só será destituído dele através de processo administrativo ou judicial assegurada a ampla defesa, possibilitando o pleno exercício do cargo (HACK, 2010).

Contudo, essa segurança que garante a permanência no exercício do cargo pode ocasionar em algumas situações que interferem diretamente na motivação do servidor e no seu desempenho perante a prestação do serviço público. Por isso, a seguir serão destacadas duas abordagens relevantes que influenciam na motivação dos servidores e necessitam da atenção e avaliação por parte dos gestores públicos, com o intuito de desenvolver e manter o bom desempenho e a eficiência nos serviços prestados aos usuários.

- O baixo desempenho e a falta de qualidade e eficiência dos serviços prestados à população pelos servidores

Essa primeira abordagem apresenta as principais consequências relacionadas ao comportamento do servidor e a execução das suas atividades que são ocasionadas pela garantia da estabilidade e fatores de desmotivação. De acordo com Diniz, et al. (2012, p.3):

A estabilidade seria a principal causa de acomodação dos servidores públicos, o que influenciaria diretamente a má qualidade dos serviços prestados, tanto interna (intraorganizacional) quanto externa (diretamente à sociedade). Pode-se entender a acomodação como uma postura de resignação no trabalho, o sentimento de insatisfação ou impotência que inibe o desejo de evoluir ou impede uma ação/iniciativa.

Embora não seja o único fator no setor público, a acomodação é muitas vezes relacionada diretamente à estabilidade. Com isso, afirma-se que as obrigações funcionais que abrangem o desenvolvimento das atividades e dos serviços prestados à população ficam comprometidas. Existem, também, condições desfavoráveis que permeiam desde a estrutura organizacional (devido às condições físicas inadequadas no ambiente de trabalho) até as gestões ineficientes. Os resultados apresentados são: a insatisfação - tanto da população com a qualidade do serviço, quanto do servidor em relação ao 
desempenho do seu trabalho; além disso, a baixa produtividade e a redução do nível de comprometimento com o serviço prestado e com as metas organizacionais.

Outro elemento que pode influenciar na motivação do servidor é a ausência de melhorias e o desenvolvimento efetivo de políticas públicas direcionadas aos planos de cargos e salários, e políticas de valorização e reconhecimento - visto que a possibilidade de crescimento profissional estimula o bom desempenho - apesar de o setor público apresentar essa sistemática de progressão de carreira. Nesse sentindo, Knapik (2012) destaca que para promover a motivação dos servidores não é necessário o desenvolvimento de práticas onerosas e de difícil aplicação, apenas, que sejam voltadas para o modelo de gestão participativa e de valorização pelo desempenho.

- Implementação de políticas e ações de valorização dos servidores

Faz-se necessário desenvolver programas específicos de participação e valorização dos servidores, como também, estabelecer ações de melhorias para estimular e manter a motivação. Com a finalidade de atingir resultados satisfatórios, com eficiência e eficácia na prestação de serviços e no atendimento do interesse público.

Portanto, "estabelece-se um desafio para o governo, enquanto empregador e garantidor do bem-estar da sociedade brasileira: buscar meios que mantenham níveis adequados de satisfação do quadro de pessoal, para que se possa atender bem aos anseios da sociedade" (DINIZ, et al. 2012, p.15).

Para isso, Bergue (2012) enfatiza que é importante efetivar programas específicos que buscam determinar condições viáveis para a motivação dos indivíduos, como programa de reconhecimento e de envolvimento ampliado dos servidores; de remuneração variável; bem como programa de remuneração por habilidades adquiridas; programas de benefícios e de envolvimento social (responsabilidade social); além da flexibilização do horário de trabalho.

Nesse contexto, a implementação de programas proporcionarão ao servidor a satisfação, o estímulo, bem como o comprometimento em desempenhar as atividades que lhe competem de maneira eficaz e eficiente. Para então, mantê-los motivados e dispostos a alcançar as metas organizacionais e prestar serviços com qualidade e eficiência.

Destarte, a estabilidade conforme prevista em lei, não se torna um privilégio pessoal, mas, um instrumento disposto pelo Estado que tem como finalidade a garantia da continuidade do serviço público e a eficiência dos processos, como também, a efetiva permanência do servidor com o desenvolvimento de habilidades para exercer suas atividades da melhor maneira de tal modo que qualidade seja parte integrante do serviço público; com isso, a Administração Pública tornar-se-á eficaz e atingirá a efetividade.

É relevante, portanto, depreender a situação de trabalho dos servidores e suas características como a eficiência e o compromisso com o interesse público. Além disso, os fatores já mencionados como o clima organizacional favorável e o conhecimento das necessidades dos trabalhadores que são 
decisivos para uma gestão eficiente, bem como para a motivação dos colaboradores, que leva os funcionários do setor público a desempenharem bem suas atividades. Para tanto, a análise da estabilidade como um fator determinante torna-se imprescindível, por possibilitar aos gestores públicos (que podem influenciar na motivação dos funcionários) o entendimento de que existem as duas vertentes e que é necessário que se desenvolva o aspecto positivo da estabilidade para o alcance dos objetivos organizacionais.

\section{Metodologia}

O presente estudo teve como finalidade analisar a complexidade e a influência dos fatores motivacionais e comportamentais do servidor público perante o seu desempenho e eficiência para com o serviço público, fundamentada as principais teorias motivacionais de conteúdo e processo, com enfoque na Teoria da Expectativa.

Em relação ao método de abordagem, utilizou-se da pesquisa qualitativa que é classificada por Matias-Pereira (2010) como uma pesquisa que envolve o entendimento das particularidades do comportamento dos indivíduos, com isso, não exige o uso de métodos e técnicas estatísticas já que a prioridade dessa abordagem é o processo e seu significado.

Quanto aos objetivos gerais esta pesquisa classificou-se como exploratória, já que apresentou a finalidade de tornar a temática mais evidente e desenvolver um conhecimento mais aprofundado a respeito, por isso, envolveu levantamento bibliográfico sobre o tema. Para corroborar, Gil (2010, p. 27) explana que "as pesquisas exploratórias têm como objetivo proporcionar maior familiaridade com o problema, com vistas a torná-lo mais explícito ou a construir hipóteses".

O procedimento adotado para a análise do estudo foi realizado por meio da pesquisa bibliográfica, a qual se buscou a compreensão dos fatos e comportamentos, com fundamentação teórica em livros e artigos de periódicos disponibilizados na internet.

Diante disso, GIL (2010) afirma que a pesquisa bibliográfica é essencial para a construção de dissertações, pois, é ela que trará uma legitimação teórica ao estudo, agregando maior confiabilidade sobre as informações e dados contidos na pesquisa acadêmica. Conforme a definição de Vergara (2007, p.49) "a pesquisa bibliográfica é o estudo sistematizado desenvolvido com base em material publicado em livros, revistas, jornais, redes eletrônicas, isto é, material acessível ao público em geral.”

A análise bibliográfica é dada por meio de levantamentos e observações sistemáticas, então, para a elaboração deste trabalho utilizou-se o estudo das bibliografias e artigos relacionados aos seguintes temas: administração pública e o serviço público; motivação; eficiência; abordou-se, ainda, sobre as principais teorias motivacionais; o processo de motivação no ambiente organizacional; e também, destacou-se a estabilidade como fator motivacional influente no desempenho do serviço público. 


\section{Considerações Finais}

Com a finalidade de tornar as práticas administrativas governamentais mais eficientes, por meio da contribuição de servidores motivados, que o presente estudo foi desenvolvido, isso, para melhor atender aos interesses públicos. Assim, por meio do estudo realizado buscou-se disseminar o conhecimento, bem como despertar o interesse de novas pesquisas uma vez que os elementos apresentados levantarão hipóteses de solução para uma posterior implementação de melhorias. Além disso, por meio da análise das teorias motivacionais é possível adequá-las à realidade organizacional e, então, desenvolver estratégias eficazes para manter os funcionários motivados.

Pode-se afirmar, conforme apresentado nas principais teorias, que a motivação varia de acordo com as necessidades e expectativas de cada indivíduo. Diante disso, o presente estudo buscou identificar e analisar os fatores determinantes para a motivação e o desempenho positivo dos servidores públicos. Para tanto, é necessário que o gestor público respeite as peculiaridades individuais, seja capaz de reconhecer o que impulsiona os seus colaboradores a serem mais produtivos e propicie um bom clima organizacional.

A motivação dos servidores é considerável para uma administração pública eficiente e está relacionada ao clima organizacional favorável; resultante, também, de bons relacionamentos interpessoais e uma gestão eficiente, a consequência disso é um profissional mais comprometido. Ademais, é exemplo de contribuição para a motivação do servidor, a garantia da estabilidade; embora, faça parte de duas abordagens opostas: a segurança e a acomodação - decorrentes dela.

Ressalta-se, portanto, que motivar pessoas não é simples; porém, acarreta em diversos benefícios. Nessa perspectiva, o gestor público deve aplicar estratégias de melhoria do ambiente de trabalho, desenvolver a convergência dos interesses institucionais e pessoais, bem como a manutenção da motivação dos colaboradores. Isso resultará em qualidade dos serviços e maiores indicadores de produtividade e satisfação dos usuários do serviço público.

\section{Referências}

BERGUE, S. T. Cultura e mudança organizacional. Florianópolis: Departamento de Ciências da Administração / UFSC; [Brasília]: CAPES: UAB, 2010.

BERGUE, S. T. Comportamento Organizacional. Florianópolis: Departamento de Ciências da Administração / UFSC; [Brasília]: CAPES: UAB, 2012.

BRASIL. Constituição (1988). Constituição da República Federativa do Brasil. Brasília, DF, Senado, 1998.

CHIAVENATO, I. Administração geral e pública. - 3. ed. -Barueri, SP: Manole, 2012. 
Id on Line Revista Multidisciplinar e de Psicologia

Id on Line Multidisciplinary and Psychology Journal

DINIZ et al. Estabilidade no Emprego e o Comportamento do Servidor Público de Municipal. In: IX Simpósio de Excelência em Gestão e Tecnologia - SEGeT, Resende - RJ, Brasil, 24 - 26 out. 2012. Disponível em: <http://www.aedb.br/seget/arquivos/artigos12/

1201677.pdf >. Acesso em: 08 abr. 2016.

DI PIETRO, M. S. Z. Direito administrativo. - 27. ed. - São Paulo: Atlas, 2014.

GIL, A. C. Como elaborar projetos de pesquisa. 5. Ed. São Paulo: Atlas, 2010.

HACK, E. Noções preliminares de direito administrativo e direito tributário - 3 ed. rev., atual.e ampl. Curitiba: Ibpex, 2010.

KNAPIK, J. Gestão de pessoas e talentos. Curitiba: InterSaberes, 2012.

MATIAS-PEREIRA, J. Manual de Metodologia da Pesquisa Científica. - 4. ed. - São Paulo: Atlas, 2010.

MATIAS-PEREIRA, J. Curso de Administração Pública: foco nas instituições e ações governamentais. - 3. ed. - São Paulo: Atlas, 2010.

MAXIMIANO, A. C. A. Teoria geral da administração: da revolução urbana à revolução digital. - 4. ed. - São Paulo: Atlas, 2004.

MAXIMIANO, A. C. A. Introdução à administração. - Ed. Compacta. 1. ed. - 4. reimpr. - São Paulo: Atlas, 2009.

MAXIMIANO, A. C. A. Fundamentos da Administração: introdução à teoria geral e aos processos da administração. - 3.ed. - Rio de Janeiro: LTC, 2015.

PÉREZ-RAMOS, J. Motivação no trabalho: abordagens teóricas. Psicologia-USP, São Paulo, 1(2): 127 $140,1990$.

ROBBINS, S. P. Comportamento organizacional. - 11. ed. - São Paulo: Pearson Prentice Hall, 2005.

TORRES, M. T. Estabilidade no serviço público: um fator de interferência na qualidade do serviço prestado ao cidadão. produção acadêmica - Universidade Estácio de Sá - UNESA - Campus Macaé, RJ. 2011. Disponível em: <http://www.administradores.com.br/ producao-academica/estabilidade-no-servicopublico-um-fator-de-interferencia-na-qualidade-do-servico-prestado-ao-cidadao/4026/>. Acesso em: 10 maio 2016.

VERGARA, S. C. Projetos e relatórios de pesquisa em administração. - 9. ed. - São Paulo: Atlas, 2007.

VIEIRA et al. Revista ADMpg Gestão Estratégica. Minas Gerais, v. 4, n. 1, 2011.

Como citar este artigo (Formato ABNT):

ALVES, E.S.; FREIRE, G.B.; QUEVEDO, A.P.F. Motivação no Serviço Público Resulta em eficiência. Id on Line Revista Multidisciplinar e de Psicologia, Julho de 2016, vol.,10 n.30, Supl 1. p. 302-319. ISSN 19811179 .

Recebido: 20/05/2016

Aceito: 26/05/2016 